\title{
Medical and Infectious Complications Associated with Pyelonephritis among Pregnant Women at Delivery
}

\author{
Sarah K. Dotters-Katz, R. Phillips Heine, and Chad A. Grotegut \\ Division of Maternal-Fetal Medicine, Department of Obstetrics and Gynecology, Duke University, \\ DUMC Box 3967, Durham, NC 27710, USA \\ Correspondence should be addressed to Chad A. Grotegut; chad.grotegut@duke.edu
}

Received 25 April 2013; Revised 23 August 2013; Accepted 26 August 2013

Academic Editor: Lu-Yu Hwang

Copyright (C) 2013 Sarah K. Dotters-Katz et al. This is an open access article distributed under the Creative Commons Attribution License, which permits unrestricted use, distribution, and reproduction in any medium, provided the original work is properly cited.

\begin{abstract}
Objective. Pyelonephritis is a common cause of antepartum admission and maternal morbidity. Medical complications associated with pyelonephritis during delivery are not well described; thus the objective of this study was to estimate medical, infectious, and obstetric complications associated with pyelonephritis during the delivery admission. Study Design. We conducted a retrospective cohort study using the Nationwide Inpatient Sample (NIS) for the years 2008-2010. The NIS was queried for all delivery-related discharges. During the delivery admission, the ICD-9-CM codes for pyelonephritis were used to identify cases and were compared to women without pyelonephritis. A multivariable logistic regression model was constructed for various medical, infectious, and obstetric complications among women with pyelonephritis compared to women without, while controlling for preexisting medical conditions and demographics. Results. During the years 2008-2010, there were 26,397 records with a diagnosis of pyelonephritis during the delivery admission, for a rate of 2.1 per 1000 deliveries. Women with pyelonephritis had increased associated risks for transfusion, need for mechanical ventilation, acute heart failure, pneumonia, pulmonary edema, acute respiratory distress syndrome, sepsis, acute renal failure, preterm labor, and chorioamnionitis, while controlling for preexisting medical conditions. Conclusions. Pyelonephritis at delivery admissions is associated with significant medical and infectious morbidity.
\end{abstract}

\section{Introduction}

Pyelonephritis during pregnancy has the potential to cause serious morbidity to the pregnant woman. It is the most common nonobstetric indication for antepartum hospitalization, and its associated risk factors, diagnosis, and management in the antepartum period are well described [1-4]. Serious morbidity associated with pyelonephritis in pregnancy is common. Sepsis and septic shock occur secondary to pyelonephritis more frequently than secondary to any other infectious process during pregnancy [5]. Acute respiratory distress syndrome complicates approximately 1$8.5 \%$ of pyelonephritis cases $[6,7]$. Frequently, an admission to an intensive care unit is necessary.

While the implications of pyelonephritis in the antepartum period are well described, there is little data about outcomes and complications when pyelonephritis occurs at the time of delivery $[1-3,8-11]$. As these studies describe outcomes of pregnancies complicated by pyelonephritis, none of these describe specifically outcomes of patients who deliver during the admission during which they were diagnosed with pyelonephritis. The objective of this study was to expand on these studies, using a large nationwide data set, to estimate the medical, infectious, and obstetric complications associated with pyelonephritis at delivery.

\section{Materials and Methods}

2.1. Study Design. The Nationwide Inpatient Sample (NIS) from the Healthcare Cost and Utilization Project of the Agency for Healthcare Research and Quality (AHRQ) for years 2008-2010 was queried for all delivery discharges [12]. The NIS is the largest all-payer inpatient database in the United States and contains data from approximately 8 million hospital admissions from over 1,000 hospitals in 42 states (2008) to 45 states (2010). The hospitals in the NIS are stratified based on ownership, bed size, teaching status, 
TABLE 1: Demographic data at the time of delivery in hospital discharges among women with pyelonephritis compared to women without pyelonephritis, Nationwide Inpatient Sample years 2008-2010 (12,628,746 deliveries).

\begin{tabular}{|c|c|c|c|c|}
\hline & $\begin{array}{c}\text { Pyelo } \\
n=26,397\end{array}$ & $\begin{array}{c}\text { No Pyelo } \\
n=12,602,349\end{array}$ & OR (95\% CI) & $P$ value \\
\hline \multicolumn{5}{|l|}{ Race/ethnicity, $n(\%)$} \\
\hline Caucasian & $9436(35.7)$ & $5,561,876(44.1)$ & 1.0 & - \\
\hline African American & $3948(14.9)$ & $1,507,268(12.0)$ & $1.5(1.5,1.6)$ & $<0.0001$ \\
\hline Hispanic & $7644(29.0)$ & $2,418,562(19.2)$ & $1.9(1.8,1.9)$ & $<0.0001$ \\
\hline Other & $1738(6.6)$ & $1,161,608(9.2)$ & $0.9(0.8,0.9)$ & $<0.0001$ \\
\hline Missing & $3634(13.8)$ & $1,953,036(15.5)$ & - & - \\
\hline Age, yrs ${ }^{\mathrm{a}, \mathrm{e}}$ & $24.9 \pm 14.5$ & $27.6 \pm 13.7$ & - & $<0.0001$ \\
\hline Private insurance, $n(\%)^{\mathrm{e}}$ & $7421(28.1)$ & $6,252,591(49.6)$ & $0.4(0.4,0.4)$ & $<0.0001$ \\
\hline $\begin{array}{l}\text { Median house income in ZIP code of } \\
\text { lowest quartile, } n(\%)^{\mathrm{d}, \mathrm{e}}\end{array}$ & $9192(34.8)$ & $3,331,368(26.4)$ & $1.5(1.5,1.5)$ & $<0.0001$ \\
\hline LOS, days $s^{\text {be }}$ & $3(2,4)$ & $2(2,3)$ & - & $<0.0001^{\mathrm{c}}$ \\
\hline Total charges, $\$^{\mathrm{b}, \mathrm{e}}$ & $11,175(7030,19,174)$ & $10,000(6785,15,090)$ & - & $<0.0001^{\mathrm{c}}$ \\
\hline \multicolumn{5}{|c|}{$\begin{array}{l}\text { aValues are mean } \pm \text { SD. } \\
{ }^{b} \text { Values are median (quartile). } \\
{ }^{c} \text { Wilcoxon rank sum. } \\
{ }^{d} \text { Median house income in ZIP code of lowest quartile defined as median income in subject's ZIP code } \$ 1-\$ 38,999 \text {. } \\
{ }^{\text {e }} \text { The numbers of missing variables for each demographic descriptor are listed as follows for women with and without pyelonephritis, respectively: age (10 } \\
[0.04 \%] \text { and } 13,490[0.1 \%]) \text {, insurance status }(50[0.2 \%] \text { and } 17,975[0.1 \%]) \text {, house income status }(475[1.8 \%] \text { and } 253,740[2.0 \%]) \text {, LOS }(0[0 \%] \text { and } 430 \\
[0.003 \%]) \text {, and total charges }(630[2.4 \%] \text { and } 288,585[2.3 \%]) \text {. }\end{array}$} \\
\hline
\end{tabular}

urban/rural location, and region. From each stratum, the NIS contains approximately $20 \%$ of United States (US) hospitals, and the sampling frame comprises $90 \%$ of all US hospital discharges. The information included in the NIS is similar to that in a typical discharge summary with safeguards to protect the privacy of individual patients, physicians, and hospitals. Weighting estimates are included for each hospitalization that allows for national estimates to be made [12].

Using the NIS for each of the years 2008-2010, all records containing a delivery discharge were identified. A delivery admission was defined as a hospitalization that included a delivery code (International Classification of Diseases, 9th Revision, Clinical Modification [ICD-9-CM] codes 74 for cesarean section; 72, 73, and 75 for vaginal delivery; V27 or 650-659 for nonspecific delivery codes) [13, 14]. Deliveries were also identified by diagnosis-related group (DRG) codes. DRG codes 765 and 766 were utilized to identify cesarean deliveries and codes 767, 768, 774, and 775 for vaginal deliveries. The ICD-9-CM codes used to identify discharges with pyelonephritis were 590.0-590.9. To identify comorbidities, both the ICD-9-CM code for a particular condition in pregnancy and the general ICD-9-CM codes were used (Supplemental Table 1 of the Supplementary Material available online at http://dx.doi.org/10.1155/2013/124102 for list of ICD-9-CM codes used).

2.2. Statistical Analysis. All admissions in the NIS for delivery were identified. Logistic regression analyses were used to compute odds ratios with 95\% confidence intervals for age, race/ethnicity, medical conditions and events, and pregnancy-related complications among women with pyelonephritis compared to women without pyelonephritis.
A multivariable logistic regression model was created controlling for age, insurance status, income quartile of residing ZIP code, and the studied preexisting medical conditions to identify the odds of various medical and obstetric complications among women with pyelonephritis compared to women without pyelonephritis. Race/ethnicity was not included in the final model due to the large number of entries in the NIS with missing race/ethnicity data. Statistical significance for all analyses was assigned as a $P$ value $<0.05$. Analyses were performed using SAS version 9.3 (SAS Institute Inc., Cary, NC) and GraphPad Prism 6.0 for Macintosh (GraphPad Software, San Diego, CA). This study protocol was reviewed and approved by the Duke University Medical Center Institutional Review Board as exempt research.

\section{Results}

During the period from 2008 through 2010, there were estimated 12,628,746 deliveries in the NIS, of those, 26,397 patient records included a diagnosis of pyelonephritis at a delivery discharge. The overall rate of pyelonephritis during delivery admission for the years 2008 through 2010 was 2.1 per 1000 deliveries.

Table 1 describes demographic information in patients with and without pyelonephritis. Women with pyelonephritis during the delivery admission were more likely to be African American or Hispanic, were younger, less likely to have private insurance, and were more likely to reside in a ZIP code whose median income was in the lowest quartile (Table 1). Race/ethnicity data was missing for $13.8 \%$ of women with pyelonephritis and for $15.5 \%$ of women without pyelonephritis. 
TABLE 2: Preexisting medical conditions present at time of delivery in hospital discharges among women with pyelonephritis compared to women without pyelonephritis, Nationwide Inpatient Sample years 2008-2010 (12,628,746 deliveries).

\begin{tabular}{|c|c|c|c|c|}
\hline Condition, $n(\%)$ & $\begin{array}{c}\text { Pyelo } \\
n=26,397\end{array}$ & $\begin{array}{c}\text { No Pyelo } \\
n=12,602,349\end{array}$ & OR $(95 \% \mathrm{CI})$ & $P$ value \\
\hline \multicolumn{5}{|l|}{ Heart disease } \\
\hline Cardiomyopathy & $39(0.1)$ & $5705(0.04)$ & $3.3(2.4,4.4)$ & $<0.0001$ \\
\hline Valvular heart disease & $108(0.4)$ & $55,209(0.4)$ & $0.9(0.8,1.1)$ & 0.513 \\
\hline \multicolumn{5}{|l|}{ Pulmonary disease } \\
\hline Asthma & $1423(5.4)$ & $410,193(3.3)$ & $1.7(1.6,1.8)$ & $<0.0001$ \\
\hline \multicolumn{5}{|l|}{ Endocrine disorders } \\
\hline Diabetes (nongestational) & $560(2.1)$ & $133,796(1.1)$ & $2.0(1.9,2.2)$ & $<0.0001$ \\
\hline Thyroid disorder & $510(1.9)$ & $299,418(2.4)$ & $0.8(0.7,0.9)$ & $<0.0001$ \\
\hline \multicolumn{5}{|l|}{ Autoimmune disorders } \\
\hline Systemic lupus erythem. & $77(0.3)$ & $16,596(0.1)$ & $2.2(1.7,2.7)$ & $<0.0001$ \\
\hline \multicolumn{5}{|l|}{ Hematologic disorders } \\
\hline Thrombophilia/APS & $141(0.5)$ & $71,313(0.6)$ & $0.9(0.8,1.1)$ & 0.516 \\
\hline Anemia & $5406(20.5)$ & $1,358,360(10.8)$ & $2.1(2.1,2.2)$ & $<0.0001$ \\
\hline Thrombocytopenia & $443(1.7)$ & $114,254(0.9)$ & $1.9(1.7,2.0)$ & $<0.0001$ \\
\hline Sickle cell/thalassemia & $86(0.3)$ & $19,559(0.1)$ & $2.1(1.7,2.6)$ & $<0.0001$ \\
\hline \multicolumn{5}{|l|}{ Drugs/alcohol/tobacco } \\
\hline Drug use & $852(3.2)$ & $164,788(1.3)$ & $2.5(2.3,2.7)$ & $<0.0001$ \\
\hline Alcohol use & $56(0.2)$ & $14,034(0.1)$ & $1.9(1.5,2.5)$ & $<0.0001$ \\
\hline Tobacco & $2531(9.6)$ & $792,389(6.3)$ & $1.6(1.5,1.6)$ & $<0.0001$ \\
\hline \multicolumn{5}{|c|}{ Chronic hypertension/renal failure } \\
\hline Chronic hypertension & $488(1.8)$ & $248,440(2.0)$ & $0.9(0.8,1.02)$ & 0.148 \\
\hline Chronic renal failure & $40(0.1)$ & $5012(0.04)$ & $3.8(2.8,5.1)$ & $<0.0001$ \\
\hline
\end{tabular}

APS: antiphospholipid antibody syndrome.

Table 2 presents preexisting medical conditions associated with pyelonephritis. Women with pyelonephritis during the delivery admission were more likely to have cardiomyopathy, asthma, diabetes, systemic lupus erythematosus, anemia, thrombocytopenia, sickle cell disease/thalassemia, or chronic renal failure compared to women without pyelonephritis. Women with pyelonephritis during the delivery admission were also more likely to use drugs, alcohol, or tobacco compared to women without pyelonephritis.

Medical complications were common among women with pyelonephritis at delivery admission. Women with pyelonephritis had increased odds of acute heart failure, deep vein thrombosis, pulmonary edema, and acute renal failure compared to women without pyelonephritis. Infection complications were also common among women with pyelonephritis. Women with pyelonephritis at a delivery admission had increased odds of pneumonia, acute respiratory distress syndrome, and sepsis compared to women without pyelonephritis. In addition, women with pyelonephritis were more likely to have a transfusion and require mechanical ventilation compared to women without pyelonephritis (Table 3).

Women with pyelonephritis were more likely to be carrying a multiple gestation or have their pregnancy complicated by preterm labor or chorioamnionitis compared to women without pyelonephritis. Cesarean delivery, gestational diabetes, preeclampsia/eclampsia/gestational hypertension, premature rupture of the membranes, and postpartum hemorrhage were all less common among women with pyelonephritis compared to women without pyelonephritis at the time of delivery admission (Table 4).

Table 5 outlines the adjusted analysis for various medical and obstetric complications at delivery while controlling for age, insurance status, income of residing ZIP code, and preexisting medical conditions in women who had pyelonephritis at the time of delivery. Most significantly, sepsis was 108 times more likely to occur among women with pyelonephritis compared to women without pyelonephritis. Other infectious complications remained significantly associated with pyelonephritis, including pneumonia, acute renal failure, pulmonary edema, and acute respiratory distress syndrome in our adjusted model. Multiple gestation, chorioamnionitis, and preterm labor were also more common in the pyelonephritis population.

\section{Discussion}

Pyelonephritis is the most common nonobstetric indication for antepartum hospitalization and is a common source of maternal and neonatal morbidity [3]. Here, we demonstrate 
TABLE 3: Medical events present at time of delivery in hospital discharges among women with pyelonephritis compared to women without pyelonephritis, Nationwide Inpatient Sample years 2008-2010 (12,628,746 deliveries).

\begin{tabular}{|c|c|c|c|c|}
\hline Condition, $n(\%)$ & $\begin{array}{c}\text { Pyelo } \\
n=26,397\end{array}$ & $\begin{array}{c}\text { No Pyelo } \\
n=12,602,349\end{array}$ & OR $(95 \% \mathrm{CI})$ & $P$ value \\
\hline Transfusion & $793(3.0)$ & $130,911(1.0)$ & $2.9(2.7,3.2)$ & $<0.0001$ \\
\hline Mechanical ventilation & $221(0.8)$ & $8807(0.07)$ & $12.1(10.6,13.8)$ & $<0.0001$ \\
\hline \multicolumn{5}{|l|}{ Cardiac events } \\
\hline Acute heart failure & $67(0.2)$ & $4523(0.04)$ & $7.1(5.5,8.9)$ & $<0.0001$ \\
\hline \multicolumn{5}{|l|}{ Pulmonary events } \\
\hline Pneumonia & $635(2.4)$ & $12,589(0.1)$ & $24.7(22.7,26.7)$ & $<0.0001$ \\
\hline Pulmonary edema & $55(0.2)$ & $2008(0.02)$ & $13.0(9.8,16.9)$ & $<0.0001$ \\
\hline Acute respiratory distress syn & $88(0.3)$ & $2798(0.02)$ & $15.0(12.1,18.5)$ & $<0.0001$ \\
\hline \multicolumn{5}{|l|}{ Thromboembolic Events } \\
\hline Pulmonary embolism & $11(0.04)$ & $3609(0.03)$ & $1.3(0.6,2.3)$ & 0.405 \\
\hline Deep vein thrombosis & $22(0.08)$ & $6352(0.05)$ & $1.6(1.03,2.4)$ & 0.022 \\
\hline \multicolumn{5}{|l|}{ Infections } \\
\hline Sepsis & $1393(5.3)$ & $5426(0.04)$ & $129(122,137)$ & $<0.0001$ \\
\hline \multicolumn{5}{|l|}{ Renal event } \\
\hline Acute renal failure & $257(1.0)$ & $6828(0.05)$ & $18.1(15.9,20.5)$ & $<0.0001$ \\
\hline
\end{tabular}

TABLE 4: Obstetric events present at time of delivery in hospital discharges among women with pyelonephritis compared to women without pyelonephritis, Nationwide Inpatient Sample years 2008-2010 (12,628,746 deliveries).

\begin{tabular}{|c|c|c|c|c|}
\hline Condition, $n(\%)$ & $\begin{array}{c}\text { Pyelo } \\
n=26,397\end{array}$ & $\begin{array}{c}\text { No Pyelo } \\
n=12,602,349\end{array}$ & OR $(95 \% \mathrm{CI})$ & $P$ value \\
\hline \multicolumn{5}{|l|}{ Obstetric events } \\
\hline Cesarean delivery & 3669 (13.9) & $4,037,688(32.0)$ & $0.3(0.3,0.3)$ & $<0.0001$ \\
\hline Operative vaginal delivery & $645(2.4)$ & $791,598(6.3)$ & $0.4(0.3,0.4)$ & $<0.0001$ \\
\hline Multiple gestation & $1392(5.3)$ & $265,839(2.1)$ & $2.6(2.4,2.7)$ & $<0.0001$ \\
\hline GDM & $982(3.7)$ & $714,105(5.7)$ & $0.6(0.6,0.7)$ & $<0.0001$ \\
\hline Prex, eclamp, gest HTN & $1271(4.8)$ & $929,959(7.4)$ & $0.6(0.6,0.7)$ & $<0.0001$ \\
\hline Preterm labor & $3696(14.0)$ & $1,048,007(8.3)$ & $1.8(1.7,1.9)$ & $<0.0001$ \\
\hline Premature rupture of membranes & $440(1.7)$ & $469,115(3.7)$ & $0.4(0.4,0.5)$ & $<0.0001$ \\
\hline Postpartum hemorrhage & $375(1.4)$ & $321,599(2.5)$ & $0.5(0.5,0.6)$ & $<0.0001$ \\
\hline Chorioamnionitis & $1285(4.9)$ & $322,282(2.5)$ & $1.9(1.8,2.1)$ & $<0.0001$ \\
\hline
\end{tabular}

Eclamp: eclampsia; GDM: gestational diabetes; gest HTN: gestational hypertension; prex: preeclampsia.

that pyelonephritis at delivery admission is also common. We reconfirm several well-known preexisting medical conditions that have been associated with pyelonephritis during pregnancy and further demonstrate that women with pyelonephritis at delivery admission are at increased risk for severe infectious complications, such as pneumonia, ARDS, and sepsis, and are also at increased risk for transfusion, requiring mechanical ventilation, acute heart failure, pulmonary edema, and acute renal failure. As our study utilized data from a large database representing the entire United States, the conclusions and findings from our analysis largely validate findings from previously noted smaller, single-center studies.

It is well known that women who develop pyelonephritis during pregnancy are at increased risk of sepsis and ARDS and require ICU admission compared to nonpregnant women who develop pyelonephritis [1-3, 5, 15]. Using the NIS, it became evident that these women are at markedly increased risk for these and other complications. Women with pyelonephritis during the delivery are over 100 times more likely to have sepsis than women who do not have pyelonephritis. Pneumonia was 18 times more likely in women with pyelonephritis, and ARDS and pulmonary edema were both 11 times more likely to occur in this population. There was no difference in the risk for pulmonary emboli or deep vein thrombosis, suggesting an inflammatory mechanism for lung injury not a coagulationrelated mechanism. These findings illustrate that women with pyelonephritis at delivery are at risk for significant morbidity.

Belkin et al. utilized the NIS from a single year, 2006, to identify demographic data among women admitted at any time during pregnancy with pyelonephritis [15]. Similar 
TABLE 5: Multivariable logistic regression analysis for the listed outcomes among women with pyelonephritis compared to women without pyelonephritis, while controlling for age, private insurance, residing in a ZIP code with annual income at lowest quartile, cardiomyopathy, asthma, diabetes, thyroid disorders, systemic lupus erythematous, anemia, thrombocytopenia, sickle cell disease, drug use, alcohol use, tobacco use, chronic hypertension, and chronic renal failure.

\begin{tabular}{|c|c|c|}
\hline & $\begin{array}{c}\text { Adjusted OR } \\
(95 \% \mathrm{CI})\end{array}$ & $P$ value \\
\hline Transfusion & $1.8(1.7,2.0)$ & $<0.0001$ \\
\hline Mechanical ventilation & $10.9(9.5,12.5)$ & $<0.0001$ \\
\hline \multicolumn{3}{|l|}{ Cardiac events } \\
\hline Acute heart failure & $6.5(4.9,8.5)$ & $<0.0001$ \\
\hline \multicolumn{3}{|l|}{ Pulmonary events } \\
\hline Pneumonia & $18.5(17.0,20.1)$ & $<0.0001$ \\
\hline Pulmonary edema & $11.3(8.6,14.9)$ & $<0.0001$ \\
\hline $\begin{array}{l}\text { Acute respiratory distress } \\
\text { syndrome }\end{array}$ & $11.6(9.3,14.3)$ & $<0.0001$ \\
\hline \multicolumn{3}{|l|}{ Thromboembolic events } \\
\hline Pulmonary embolism & $1.1(0.6,2.0)$ & 0.858 \\
\hline Deep vein thrombosis & $1.6(1.02,2.4)$ & 0.038 \\
\hline \multicolumn{3}{|l|}{ Infections } \\
\hline Sepsis & $108(101,115)$ & $<0.0001$ \\
\hline \multicolumn{3}{|l|}{ Renal event } \\
\hline Acute renal failure & $14.7(12.9,16.7)$ & $<0.0001$ \\
\hline \multicolumn{3}{|l|}{ Obstetric events } \\
\hline Cesarean delivery & $0.3(0.2,0.4)$ & $<0.0001$ \\
\hline Operative vaginal delivery & $0.4(0.3,0.4)$ & $<0.0001$ \\
\hline Multiple gestation & $2.9(2.8,3.1)$ & $<0.0001$ \\
\hline GDM & $0.7(0.7,0.8)$ & $<0.0001$ \\
\hline Prex, eclamp, gest HTN & $0.6(0.5,0.6)$ & $<0.0001$ \\
\hline Preterm labor & $1.7(1.5,1.8)$ & $<0.0001$ \\
\hline Premature rupture of membranes & $0.4(0.4,0.5)$ & $<0.0001$ \\
\hline Postpartum hemorrhage & $0.4(0.4,0.5)$ & $<0.0001$ \\
\hline Chorioamnionitis & $1.7(1.6,1.8)$ & $<0.0001$ \\
\hline
\end{tabular}

Eclamp: eclampsia; GDM: gestational diabetes; gest HTN: gestational hypertension; Prex: preeclampsia.

to our study, they found that women less than 20 and women of African American or Hispanic race/ethnicity were at higher risk for pyelonephritis in pregnancy, though they did not compare these demographics to women without pyelonephritis. They found that women with pyelonephritis had associated risk for sepsis (2.0\%), anemia (22.4\%), diabetes $(3.7 \%)$, and preterm labor $(3.8 \%)$, but again, they did not determine the rate of these outcomes among women without pyelonephritis [15]. In our study, by analyzing data only at admissions for delivery, rather than at antepartum admission, we were able to estimate outcomes for individuals, rather than hospitalizations, as women could possibly have more than one antepartum hospitalization during a pregnancy but only a single hospitalization per woman per pregnancy. Additionally, by examining discharge data, obstetric outcomes data could be captured, which would not be available using antepartum discharges. Lastly, we were able to calculate ORs for associated complications among women with pyelonephritis since we also determined the rates of these events in pregnant women at delivery without pyelonephritis.

Our study has limitations. Our findings rely on a large discharge database, and therefore we are unable to determine if the associated preexisting medical conditions caused pyelonephritis, or if pyelonephritis was causative of the observed medical and obstetric events that were more common among women with pyelonephritis. Regardless, our data demonstrate that pyelonephritis is at least associated with these events. Next, there is no way to ascertain if coded preexisting medical conditions were active at the time of delivery. Furthermore, preexisting conditions or medical/obstetric events occurring at delivery would have been missed if the variable was not coded. Therefore, we may be underrepresenting some conditions or events. Finally, neonatal discharge records are not linked to maternal discharge records within the NIS; thus, we are unable to provide information on neonatal outcomes among those neonates born to women with pyelonephritis.

Discharge databases are also open to questions regarding the accuracy of coding. Yasmeen et al. recently assessed the accuracy and reliability of obstetric discharge databases and found them to provide helpful information [16]. Thus, despite the limitations of the NIS database, the study design allows the examination or relatively rare disorders using a large numbers of pregnancies. In doing so, odds ratios and maternal morbidity rates for medical conditions, pregnancyrelated conditions, and pregnancy outcomes that would have otherwise been difficult to quantify can be estimated. Our multivariable logistic regression model attempted to identify an independent association of pyelonephritis with various medical and obstetric outcomes. In doing so, we controlled for clinically relevant preexisting medical conditions and social factors that are known to be commonly associated with pyelonephritis. In using a database such as the NIS, it is impossible to account for all potential confounders, and as such we acknowledge this limitation.

In summary, this dataset reaffirms many of the known risk factors for pyelonephritis, including minority race, young age, lower socioeconomic status, nongestational diabetes, and sickle cell disease, but also uniquely examines preexisting medical conditions and medical and obstetric complications among women with pyelonephritis occurring at delivery. Many women with pyelonephritis at delivery were found to have other associated infectious complications such as sepsis, pneumonia, and acute respiratory distress syndrome. It is unknown if pyelonephritis was directly causative of these outcomes, and future research is warranted.

\section{Disclosure}

This paper was presented at the 2013 Annual Meeting of the Infectious Diseases Society for Obstetrics and Gynecology (IDSOG), Santa Ana Pueblo, NM, August 8-10, 2013. 


\section{Conflict of Interests}

The authors report no conflict of interests.

\section{References}

[1] F. G. Cunningham, G. B. Morris, and A. Mickal, "Acute pyelonephritis of pregnancy: a clinical review," Obstetrics and Gynecology, vol. 42, no. 1, pp. 112-117, 1973.

[2] L. C. Gilstrap III, F. G. Cunningham, and P. J. Whalley, "Acute pyelonephritis in pregnancy: an anterospective study," Obstetrics and Gynecology, vol. 57, no. 4, pp. 409-413, 1981.

[3] J. B. Hill, J. S. Sheffield, D. D. McIntire, and G. D. Wendel Jr., "Acute pyelonephritis in pregnancy," Obstetrics and Gynecology, vol. 105, no. 1, pp. 18-23, 2005.

[4] L. C. Gilstrap III and S. M. Ramin, "Urinary tract infections during pregnancy," Obstetrics and Gynecology Clinics of North America, vol. 28, no. 3, pp. 581-591, 2001.

[5] C. C. Snyder, J. R. Barton, M. Habli, and B. M. Sibai, "Severe sepsis and septic shock in pregnancy: indications for delivery and maternal and perinatal outcomes," The Journal of MaternalFetal \& Neonatal Medicine, vol. 26, no. 5, pp. 503-506, 2013.

[6] F. G. Cunningham, M. J. Lucas, and G. D. V. Hankins, "Pulmonary injury complicating antepartum pyelonephritis," American Journal of Obstetrics and Gynecology, vol. 156, no. 4, pp. 797-807, 1987.

[7] L. Galajdova, "Pulmonary dysfunction in acute antepartum pyelonephritis and other pregnancy infections," Journal of Obstetrics and Gynaecology, vol. 30, no. 7, pp. 654-658, 2010.

[8] P. Sharma and L. Thapa, "Acute pyelonephritis in pregnancy: a retrospective study," Australian and New Zealand Journal of Obstetrics and Gynaecology, vol. 47, no. 4, pp. 313-315, 2007.

[9] E. H. Kass, "Pyelonephritis and bacteriuria. A major problem in preventive medicine," Annals of internal medicine, vol. 56, pp. 46-53, 1962.

[10] E. Farkash, A. Y. Weintraub, R. Sergienko, A. Wiznitzer, A. Zlotnik, and E. Sheiner, "Acute antepartum pyelonephritis in pregnancy: a critical analysis of risk factors and outcomes," European Journal of Obstetrics Gynecology and Reproductive Biology, vol. 162, no. 1, pp. 24-27, 2012.

[11] J. C. Dawkins, H. M. Fletcher, C. A. Rattray, M. Reid, and G. Gordon-Strachan, "Acute pyelonephritis in pregnancy: a retrospective descriptive hospital based-study," ISRN Obstetrics and Gynecology, vol. 2012, Article ID 519321, 6 pages, 2012.

[12] Healthcare Cost Utilization Project HCUP, "Overview of the Nationwide Inpatient Sample (NIS)," http://www.hcup-us .ahrq.gov/nisoverview.jsp, 2013.

[13] A. H. James, C. D. Bushnell, M. G. Jamison, and E. R. Myers, "Incidence and risk factors for stroke in pregnancy and the puerperium," Obstetrics and Gynecology, vol. 106, no. 3, pp. 509516, 2005.

[14] A. H. James, M. G. Jamison, M. S. Biswas, L. R. Brancazio, G. K. Swamy, and E. R. Myers, "Acute myocardial infarction in pregnancy: a United States population-based study," Circulation, vol. 113, no. 12, pp. 1564-1571, 2006.

[15] A. Belkin, A. Levy, and E. Sheiner, "Perinatal outcomes and complications of pregnancy in women with immune thrombocytopenic purpura," The Journal of Maternal-Fetal \& Neonatal Medicine, vol. 22, no. 11, pp. 1081-1085, 2009.

[16] S. Yasmeen, P. S. Romano, M. E. Schembri, J. M. Keyzer, and W. M. Gilbert, "Accuracy of obstetric diagnoses and procedures in hospital discharge data," American Journal of Obstetrics and Gynecology, vol. 194, no. 4, pp. 992-1001, 2006. 


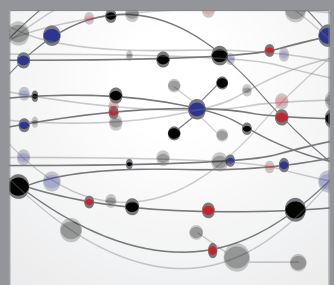

The Scientific World Journal
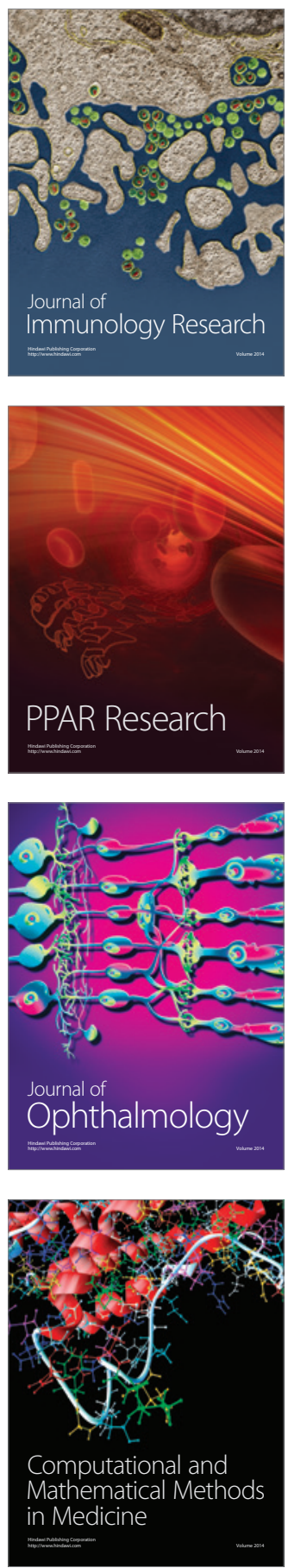

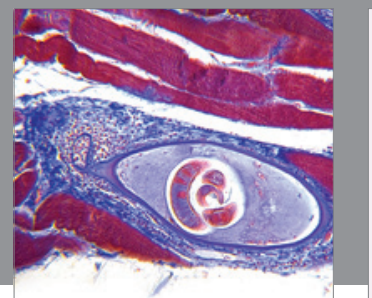

Gastroenterology

Research and Practice
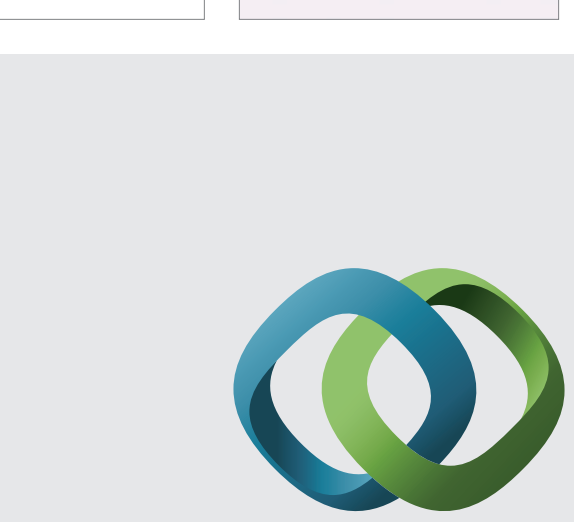

\section{Hindawi}

Submit your manuscripts at

http://www.hindawi.com
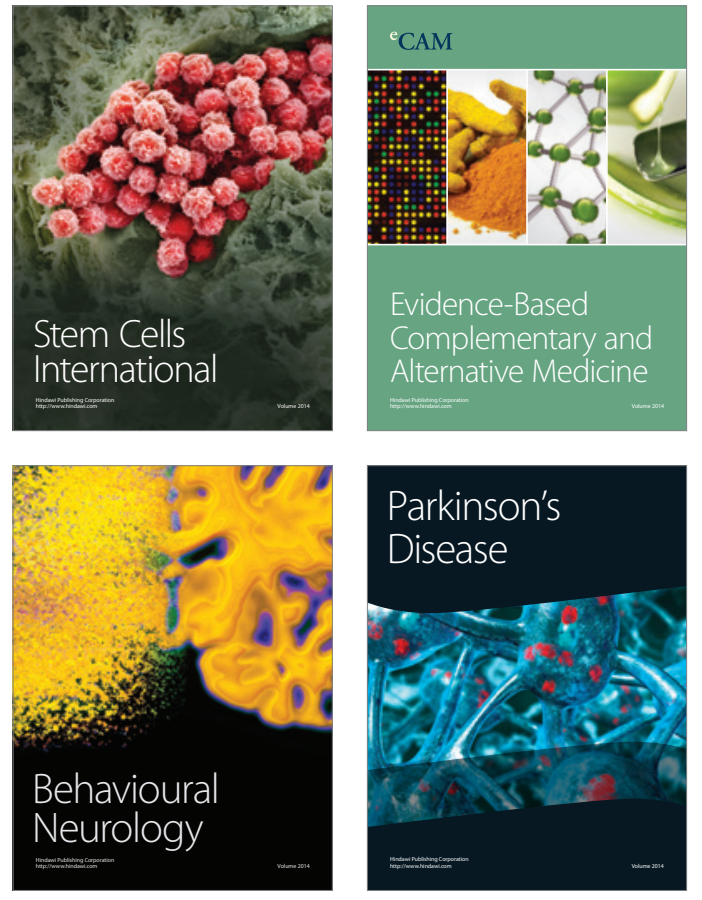
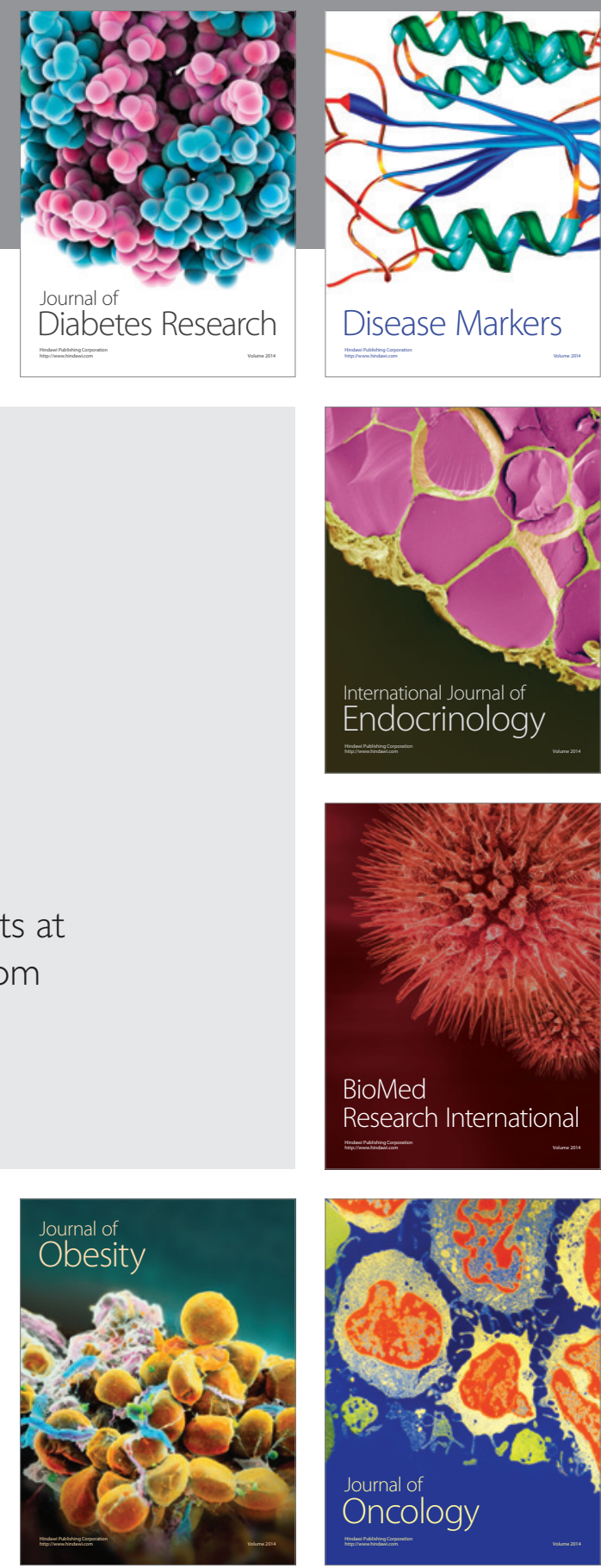

Disease Markers
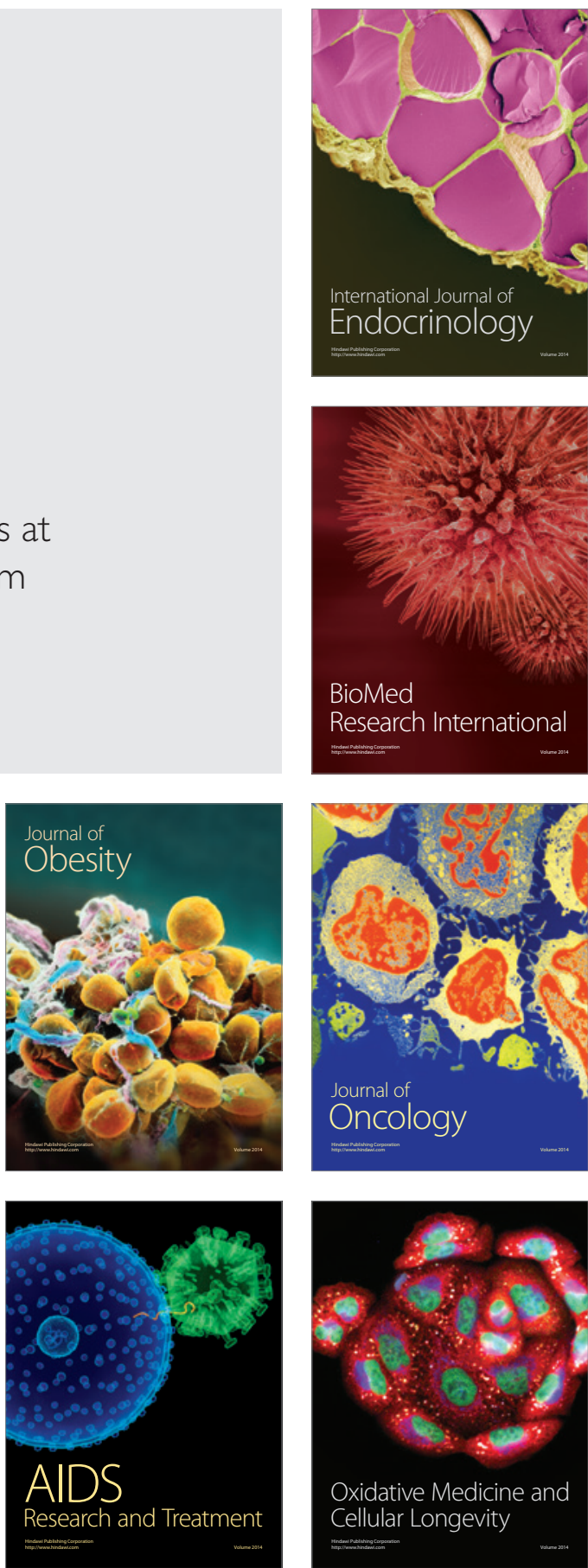